D.E.L.T.A., Vol. 15, Nº 2, 1999 (343-353)

Questões e Problemas/SQuib

\title{
CONTRIBUIÇÃo PARA O ESTUdO DO PSEUdOPREFIXO EM PORTUGUÊS
}

(Contribution to the study of pseudoprefix in Portuguese)

Paulo Mosânio Teixeira DuARTe (Universidade Federal do Ceará)

ABSTRACT: In this article we examine some points of view about pseudoprefix, namely that of Ferreira (1990), of Li Ching (1973) and of Iordan and Manoliu (1980). We emphasize the contribuitions of Iordan and Manoliu as a starting point to analyse the proposal of Carvalho (1974), based upon the secondary stress of pseudoprefix, which is able to explain its brachysemic uses.

Resumo: Neste artigo examinamos alguns pontos de vista sobre o pseudoprefixo, entre os quais o de Ferreira (1990), o de Li Ching (1973), Iordan e Manoliu (1980). Enfatizamos Iordan e Manoliu como ponto de partida para analisar a proposta de Carvalho (1974), baseada no acento secundário do pseudoprefixo, que possibilita explicar seus usos braquissêmicos.

KEY-WoRds: Root; Prefix; Pseudoprefix; Brachysemy; Stress.

Palavras-Chave: Raiz; Prefix; Pseudoprefixo; Braquissemia; Acento.

0. Introdução

Se nos deixarmos guiar pelos meros significados dos elementos estruturais do lexema pseudoprefixo, verificamos que eles significam no conjunto 'falso prefixo', o que já sinaliza um aspecto importante, embora ainda genérico: o prefixo é o termo de comparação em relação ao qual devemos entender o pseudoprefixo. Perguntamo-nos então: sob que aspecto(s) distintivo(s) devemos compreender o pseudoprefixo? Em outras palavras: justifica-se a postulação de uma entidade em morfologia com diferenças (bem como com semelhanças) comparativamente ao afixo inicial? Como o conhecimento é cumulativo, decidimos tomar algumas propostas como pontos de partida, quer para negá-las, quer para afirmá-las.

O conceito de pseudoprefixo já se encontra não apenas em obras de extração estritamente 'lingüística', mas também de extração normativogramatical, como a de Cunha e Cintra (1985) ${ }^{1}$ em língua portuguesa, que já faz 
referências aos compêndios de Li Ching (1973), Iordan e Manoliu (1980) e Carvalho (1974). Assaltou-nos o questionamento: em que medida os autores referidos por Cunha e Cintra tratam da mesma realidade conceptual? Não estaríamos perante realidades idênticas apenas no plano nominal? Afinal, é comum, em lingüística, o uso polissêmico de um termo. Por outro lado, é completamente compreensível que haja discrepâncias conceituais, uma vez que as perspectivas variam e, com elas, os objetos.

Nosso trabalho se justifica como uma revista de algumas perspectivações sobre o pseudoprefixo, para o devido exame crítico das mesmas, e como uma contribuição pessoal para o estudo da referida entidade, a partir de indícios estruturais que julgamos pertinentes.

\section{O pseudoprefixo: noção controversa}

Ferreira (1990), aludindo ao pseudoprefixo, trata-o como noção dispensável, mas não porque seja uma noção impertinente. Muito pelo contrário, segundo a lingüista portuguesa, a sua formulação é explicável e bastante pertinente. O problema que aduz é outro. A sua utilização, diz-nos ela, levanta inúmeras questões, como por exemplo, a de saber onde integrar entradas lexicais formadas de pseudoprefixo, se na derivação ou na composição. Ferreira lida com a noção como se ela fosse dispensável apenas por questões de comodidade ou de simplificação teórica. Ela argumenta que, em nível pedagógico, o conceito de pseudoprefixo é não apenas um complicador no que tange à taxonomia, mas também um incômodo no ensino da língua, porque pressupõe conhecimentos especializados. Ora, o estudo de prefixos e radicais, nos pormenores, também suscita polêmicas, o que não deve constituir obstáculo para a análise científica dos mesmos. Convém somente separar aspectos de natureza científica dos de natureza pedagógica.

É justamente no domínio científico que reside o ponto fraco da exposição feita por Ferreira, pois a autora parece inclinada a adotar o critério da produtividade em termos numéricos, o que é de natureza extralingüística: serve, por exemplo, para aferir os outputs das regras de formação de palavras, mas não para fundamentar esta ou aquela nomenclatura. Ademais, a lingüista não atentou para o fato de haver disparidade conceitual na identificação do pseudoprefixo, semelhantemente a Cunha e Cintra (1985), que, ao postularem a existência do referido elemento, se referem aos estudiosos Iordan e Manoliu

${ }^{1}$ Em italiano, há a gramática de Sensini (1990), que se baseia substantcialmente na proposta de Li Ching (1973) e na de Iordan e Manoliu (1980). 
(1980), Li Ching (1973) e Carvalho (1974) como se eles atribuíssem ao pseudoprefixo uma conceituação unívoca ${ }^{2}$. Detenhamo-nos, como ponto de partida para nossa discussão, na proposta de Iordan e Manoliu ${ }^{3}$.

Os autores julgam que entre prefixos e pseudoprefixos há semelhanças e sobretudo diferenças. A semelhança mais saliente (e mais banal) reside no fato de que uns e outros se antepõem à palavra. No tocante às diferenças :

a) os pseudoprefixos provêm de preposições e adjetivos, não apenas de advérbios e preposições, como os prefixos;

b) os pseudoprefixos se distinguem dos prefixos pela origem e pela cronologia: aqueles, de procedência grega ou latina, são de introdução relativamente recente, apresentam caráter culto e neológico e são usados para cunhar termos técnicos e científicos;

c) os pseudoprefixos geralmente não ostentam grande rendimento e

d) os pseudoprefixos apresentam um sentido menos estável que o dos prefixos.

A primeira diferença, por si só, não basta, pois é de caráter parcial. Os prefixos e pseudoprefixos, afinal, têm em comum o fato de serem provenientes de preposições e advérbios. Cumpre acrescentar que a citada diferença não é de cunho estrutural, uma vez que balizada na diacronia.

A segunda diferença não nos parece relevante e consistente. Criar um novo termo em função de fatores externos à língua implica em multiplicar as entidades além do necessário. Batizar termos apenas para dar conta de criações neológicas de caráter técnico-científico não parece bom procedimento, já que decorre do fator tempo, exterior à língua.

O terceiro critério, concernente à produtividade em termos de número, como um fim em si mesmo, igualmente não se nos afigura sólido o bastante

2 Além dos autores acima citados, há de citar-se Cárdenas (1978), que conjuga os critérios semânticos e formais ao estatístico. Para o autor, um prefixo não funciona jamais como uma lexia simples (nominal ou verbal), embora às vezes seja equivalente, quanto ao conteúdo, a um relator. O pseudoprefixo, ao contrário, pode funcionar como lexia simples, com valor ou não exclusivamente de relator. Ainda segundo Cárdenas, a freqüência distributiva serve para estabelecer os conceitos de prefixo e pseudoprefixo.

${ }^{3}$ Excluímos Sandmann (1989), que já foi objeto de um outro trabalho nosso (Duarte, 1998). O autor parte do princípio distribucional de que o prefixóide (termo que usa em lugar de pseudoprefixo) tem identidade formal com a forma livre, embora desta divirja quanto aos contextos. É o caso de sobre, em sobrevoar, de mal, em maljeitoso. 
para opor o pseudoprefixo ao prefixo. Todavia, mesmo sendo admitido, há que fazer-se objeção contra sua natureza empírica. Li Ching (1973), que trata os pseudoprefixos essencialmente em função do mesmo fator cronológico adotado por Iordan e Manoliu, comprova justamente o contrário: alguns, a exemplo de auto, micro e tele, exibem notável produtividade.

O quarto critério, por fim, embora pareça fundado no sentido etimológico, pode ser operacionalizado. Os autores sugerem a possibilidade de determinados elementos iniciais, como auto e foto, poderem ser usados no lugar do lexema inteiro em que se inserem. Eventualmente, tais elementos podem servir de base para formação de itens lexicais, o que configura recomposição $o^{4}$, segundo proposta de Bessa (1978). Damos como exemplos:

a) lexema: televisão / forma reduzida: tele / recomposição: telecurso;

b) lexema: fotografia / forma reduzida: foto / recomposição: fotonovela;

c) lexema: automóvel / forma reduzida: auto / recomposição: auto-estrada;

d) lexema: telefone / forma reduzida: tele / recomposição: tele-amizade.

A redução se associa ao fenômeno da braquissemia, que consiste no emprego de parte do lexema por todo ele. Nos casos acima, como o corte faz destacar elementos estruturais, tem-se o que Rocha (1998: 182) denomina derivação truncada estrutural. Abaixo estudamos o fenômeno, relacionandoo ao critério fonológico estabelecido por Carvalho (1974: 554), tomado como ponto de partida para a nossa argumentação.

2. O pseudoprefixo: o critério fonológico e a braquissemia

Existem, entre os morfemas prefixados, aqueles caracterizados pela presença de uma acento secundário, do qual resulta um esquema acentual análogo ao dos sintagmas fônicos. Sobre eles, afirma Carvalho: "distinguemse dos restantes prefixos, por possuir, cada um deles, uma significação mais ou menos delimitada e presente à consciência dos falantes, de tal modo que o

${ }^{4}$ Recomposição é termo que Bessa tomou a Martinet (1973: 137), que o usou, no entanto, para batizar formações híbridas como televisão e teleguiado, cujo primeiro elemento é altamente recorrente.

${ }^{5}$ Freitas (1981: 129) contra-argumenta, afirmando que o estabelecido acima não permite diferenciar estes elementos mórficos, de acento secundário, dos verdadeiros prefixos. Na verdade, Freitas focaliza apenas o aspecto semântico, constante da expressão possuírem uma significação mais ou menos delimitada e presente à consciência dos falantes e negligencia dois aspectos formais: a pauta acentual e a quase sintagmaticidade do todo a que os pseudoprefixos pertencem. 
significado do todo a que pertencem se aproxima de um conceito complexo, e portanto do de um sintagma" (1974: 554) .

Carvalho se refere a elementos como inter, intra, extra, super, supra, entre outros. Nas formações de que participam, a exemplo de extracurricular, interplanetário, infra-estrural, intramuscular, super-computador e suprapartidário, comportam-se como um vocábulo fonológico. É comum, na escrita descuidada, que eles sejam separados da base por espaço em branco, uma vez que os falantes os percebem como entidades dotadas de autonomia próxima da da palavra. Nós próprios já colhemos alguns exemplos no tocante a esse indício ortográfico. Exemplificamos:

a) super nova 2 (programação do canal 18 da rede de TV a cabo);

b) super férias (exemplo do caderno Cidades do jornal O Povo, de 04 de junho de 1999);

c) mini caldo de carne (exemplo colhido no restaurante L'escale, de Fortaleza);

d) mini sanduíche (exemplo obtido no restaurante Duda's Burguer, de Fortaleza);

e) multi pedras (exemplo encontrado em uma casa de material de construção, em Fortaleza).

O uso indiscriminado do hífen por parte de quem não conhece a regra para esse recurso gráfico também pode servir de meio para a identificação do pseudoprefixo.

Ilustramos abaixo a proposta de Carvalho, assinalando com o número 3 a sílaba tônica e, com o número 2, a subtônica.

interpanetário

2

extracurricular

2
3

3 supercomputador

2

3

infra-estrutural

2

3

Alguns elementos de pauta acentual secundária são relacionados com um tipo de braquissemia, a derivação truncada estrutural, já mencionada na secção anterior, a qual, pouco freqüente, consiste no corte de um elemento estrutural da palavra. Constituem exemplos: 


$\begin{array}{ll}\text { multinacional } & \text { èmulti } \\ \text { vice-presidente } & \text { èvice } \\ \text { ex-marido } & \text { èx } \\ \text { microcomputador } & \text { èmicro } \\ \text { pré-vestibular } & \text { èpré } \\ \text { pós-graduação } & \text { èpós } \\ \text { homossexual } & \text { èhomo } \\ \text { heterossexual } & \text { èhetero } \\ \text { hiperinflação } & \text { èhiper }\end{array}$

Este tipo de braquissemia permite distinguir elementos mórficos, como hiper e vice de outros como in- $e$ des- são verdadeiros prefixos. Por isso, convém denominá-los pseudoprefixos, que possuem estatuto muito semelhante ao da palavra, no referente à pauta acentual.

A braquissemia, descrita nos termos acima, implica o fenômeno da conversão substantival, através da qual o elemento braquissemicamente empregado se torna núcleo de funções sintáticas típicas de substantivos.

Alegar-se-ia que a palavra apagada está pressuposta, o que é indiciado pelo fato de alguns elementos conversos serem refratários à flexão, a exemplo de: o pré/*os prés, a pós/*as poses, a hiper/*as híperes. Há, todavia, casos em que o elemento braquissêmico recebe a marca superficial da flexão: as múltis, as máxis, as teles, os micros, os vices.

A forma braquissêmica pode dar lugar a novas formações, conforme nos mostra Alves (1990: 26), com os exemplos: supermicros, em lugar de supermicrocomputadores, e supermínis, em lugar de superminicomputadores. Nós próprio já nos deparamos com um exemplo de derivação sufixal: micreiro. Acresça-se a possibilidade de recomposição, sugerida por Iordan e Manoliu (1980), referidos na secção supra: teledramaturgia, telecurso, homofobia.

Em suma, a braquissemia relaciona-se com a substantivação. O substantivo gerado pode submeter-se, adicionalmente, a uma escala de parâmetros morfológicos, nomeadaamente: a) a flexão; b) a formação de derivados; c) a recomposição. Com base nesses critérios, hiper e pós são de substantivação mais precária, porque atendem apenas à condição básica: ser

${ }^{6}$ Há casos curiosos, a exemplo de micro que pode ligar-se braquissemicamente a um adjetivo: micro e pequena empresa, e de ex, que se comporta semelhantemente a micro: $o$ atual marido e o ex. 
núcleo de SN. No extremo, encontra-se micro, que se submete não apenas à condição básica, mas também aos três critérios. Tele, intermediariamente, atende ao requisito básico e aos critérios a) e c).

O pseudoprefixo pode relacionar-se também com outro tipo de braquissemia, de natureza contextual, bem mais produtiva e sistemática, em que um dos elementos, a base, é subtraído em virtude de ser empregado no vocábulo seguinte ${ }^{6}$. Pode atingir formações dessubstantivais e deadjetivais:

Observe-se que pode ocorrer, no caso das formações dessubstantivais, a ausência do elemento na segunda formação:

a) a macroestrutura e a micro;

b) a superestrutura e a infra;

c) a maxidesvalorização e a mini.

Esta redução de natureza contextual das formações com pseudo prefixos assemelha-se à das formações em mente: suave e delicadamente (< suavemente e delicadamente).

Em suma, a braquissemia contextual decorre do fato de o pseudo prefixo ter um nítido acento secundário. Por isso, ela é viabilizada num exemplo como este abaixo:

O lingüista estuda a pré- e a pós-posição do sujeito.

Todavia, não é possível um exemplo como este:

*O lingüista estuda a pré- e a pós-posição. (<preposição e posposição)

Sandmann (1992) faz algumas ponderações contra a braquissemia contextual como critério:

Excluir do rol de prefixos os formativos que apresentem qualquer grau de mobilidade (Basílio, 1990, 6) parece envolver aspectos problemático, pois formativos cujo caráter de sufixos ninguém discute também podem apresentar mobilidade: "papai só se contentava se fosse um érrimo em tudo" de monografia de aluna de pós-graduação, 'de nada adiantará aumentar o número de deputados enquanto forem eleitos, apenas, fisiologias, lobistas, sindicalistas e outros istas' (Folha, 17/7/90, p. A-3)(...) Não se discute que há prefixos mais fácil ou 
comumente móveis do que outros. Soa bem normal uma frase como "Ela é responsável pelo tratamento pré e pós-operatório". Ou estes outros: “(...) este argumento deve ser música para os $68 \%$ de analfabetos ou semi, entre os 80 milhões de eleitores. (Folha, 26/10/89, p. B-11) e “(...) O homenageado (...) confabula com o ex e atual Carlos Von Schmidt." (Folha, 29/10/89, p. F-1). Ma quem dirá que são inteiramente inaceitáveis seqüências como não a mas antiética, não se deve se mas conduzir a jovem desnorteada, principalmente em contextos de forte emocionalidade, sem falar nos textos de intenção metalingüística: Em "seduzir" $e$ "conduzir" é difícil ver sincronicamente os prefixos se $e$ com. (1992: 36-7)

A objeção do lingüista não procede. No exemplo 1, temos um processo de conversão substantival de sufixo, este muito motivado semanticamente, como ismo. $\mathrm{O}$ segundo exemplo também não convence, pois não temos a possibilidade de dizer: *fisiolog-, lob-e outros sindicalistas. Os outros casos, não a mas antiética, não se deve se mas conduzir a jovem desnorteada, são ilustrações de contraste, que levam à acentuação eventual do prefixo. Não será, contudo, lícito dizer: *a e antiético, *não se deve se e conduzir a jovem desnorteada. O último exemplo aduzido por Sandmann não procede, pois em situação de menção qualquer entidade no discurso se torna palavra.

Em suma, o teste que nos serve de fundamento é o da coordenação por $e$.

3. Acréscimos aos critérios da pauta acentual e da braquissemia.

Impõe-se adicionalmente que nos refiramos a uma nota de pé de página, com que Iordan e Manoliu tentam uma caracterização mais palpável, dos pseudoprefixos, a propósito dos exemplos electro- e tecno (romeno electro e tehno).

Idêntico a electro é o caso de tehno (esp. tecno); um e outro, ao ocupar o segundo lugar, têm uma forma plena (rom). Enquanto que o final -ic desaparece, quando ocupa o primeiro lugar na composição. Também este fato confirma a opinião de que as palavras formadas com o auxílio dos pseudoprefixos deveriam ser consideradas antes como composta que como derivadas 7 .(1980: 48)

${ }^{7}$ Idéntico a electro- es el caso de tehno- (esp. tecno-); uno y otro, al ocupar el segundo lugar, tienen forma plena (rum. electric, tehnic; esp. eléctrico, técnico). Mientras que el final -ic desaparece cuando ocupa el primer puesto de la composición. También este hecho confirma la opinión de que las palabras formadas con la ayuda de los seudoprefijos tendrían que considerace mejor como compuestas que como derivadas. 
Limitemo-nos ao português, idioma em que ocorre fenômeno semelhante, como se pode verificar nos exemplos abaixo:

\author{
formas com elemento pleno \\ termolétrico, hidroelétrico \\ zootécnico \\ eletrotérmico
}

\author{
formas com o elemento truncado \\ eletroquímica, eletrodinâmico \\ tecnocracia, tecnocrata \\ termonuclear, termobarômetro
}

Notemos que os autores não estabelecem relação derivacional entre as formas plenas e reduzidas (pelo menos, isto não está claro). Falam tão somente dos contextos da distribuição de umas e outras.

É preferível classificar exemplos como termo, eletro e tecno e congêneres como radicais, dada a geração de formas térmico, elétrico e técnico, que tem ocorrência como formas livres. Não aceitamos a hipótese da variação formal ou, em outros termos, o critério da relação entre forma reduzida e forma plena porque ela não acontece em todos os casos, conforme os exemplos: filósofo/ francófilo, fotógrafo/aerofoto, termômetro/megatermo.

Salientemos que os autores sugerem a mobilidade distribucional como outra maneira de delimitar o pseudoprefixo. Fazem-no quando se referem ao elemento filo que ilustram com filofrancez e filogermano, de um lado, efrancofil e germanofil, de outro. Por que não pseudosufixo, já que a forma também ocorre em última posição? Quiçá o melhor nome, que indica esta característica distribucional, seja radical.

As duas observações acima excluem como pseudoprefixos constituintes como os primeiros elementos das formações abaixo, os quais, embora possam ser utilizados em braquissemia, se comportam como radicais ${ }^{1}$ :

a)odontologia, forma reduzida: odonto, contextos do primeiro elemento: odontose, odontoma, odontite; periodontia;

b)eletrocardiograma, forma reduzida: eletro, contextos do primeiro elemento: elétrico, eletrificar, eletrizar;

c)hidromassagem, forma reduzida: hidro, contextos do primeiro elemento: hídrico; anidro.

\section{Conclusão}

Como vimos, o pseudoprefixo se ancora em dois parâmetros interligados:

${ }^{8}$ Os dados foram colhidos em Ferreira (1986). 
a pauta acentual e o emprego braquissêmico, este último entendido como derivação trancada estrutural e a redução contextual. Os parâmetros citados, por si sós, não bastam, pois há que se fazer descontos da possibilidade de emprego em mais de uma posição no vocábulo e a geração de derivados. Deste modo, odonto e eletro, usados em lugar de odontologia e eletrocardiograma, não constituem pseudoprefixos. O primeiro engendra derivados e goza de mobilidade; o segundo, por seu turno, gera formações sufixais. Micro é pseudoprefixo, pois os derivados supermicro e micreiro se relacionam com a forma utilizada por braquissemia em lugar de microcomputador. Em termos esquemáticos: microcomputador > micro > micreiro ou supermicro.

Convém acrescentar que alguns desses pseudoprefixos se adicionam a sintagmas nominais, a exemplo de pré e pós-revolução de 64, ex-miss Brasil, permintindo paralelos, por aproximação ou contraste, com formas livres: antes e depois da revolução de 64; a atual miss Brasil.

Isto se aplica também a outras formas afixadas como anti, em antipoluição sonora. Examinar estes casos de aposição sintagmática por parte de afixos iniciais é matéria para um outro trabalho.

REFERÊNCIAS BIBLIOGRÁFICAS

Alves, I. M. (1990) Neologismo. São Paulo: Ática.

Bessa, J. R. F. (1978) Para um Estudo sobre Nomes Compostos no Português Atual. Faculdade de Letras da UFRJ. Dissertação de mestrado inédita.

Cárdenas, H. U. (1976) Lengua y Discurso en la Creación Léxica. Madrid: Cupsa Editorial.

Carvalho, J. G. H. de (1974) Teoria da Linguagem. Vol. 2. Coimbra: Atlântida. Cunha, C. F. da \& Cintra, L. F. L. (1985) Nova Gramática do Português Contemporâneo. Rio de Janeiro: Nova Fonteira.

Duarte, P. M. T. (1998) A Identificação do Prefixo nas Diversas Abordagens Lingüísticas. Revista DELTA, 1: 141-68.

Ferreira, A. B. de H. (1986) Novo Dicionário da Língua Portuguesa. Rio de Janeiro: Nova Fronteira.

FERreIra, M. M. C. (1990) Pseudoprefixo: um Estudo Incômodo para o Estudo da Derivação Prefixal. Lisboa. Comunicação apresentada no Colóquio Internacional sobre Terminologia Científica e Técnica, CNALP.

Freitas, H. R. (1981) Princípios de Morfologia. Rio de Janeiro: Presença. Iordan, I. y M. MANoliu (1980) Manual de Lingüística Românica. Madrid: 
Gredos.

Li Ching (1973) Sobre a Formação de Palavras com Prefixos no Português Actual. Separata de Boletim de Filologia, 22: 3-100.

Martinet, A (1973) Elementos de lingüística Geral. Lisboa: Sá da Costa.

Rocha, Luiz Carlos de A (1998) Estruturas Morfológicas do Português. Belo Horizonte: Editora da UFMG

Sandmann, A. J. (1989) Formação de Palavras no Português Brasileiro Contemporâneo. Curitiba: Ícone. (1992) Morfologia Lexical. São Paulo: Contexto

Sensini, M. (1990) La Grammatica della Lingua Italiana. Milano: Arnoldo Mondadori. 